\title{
Üniversite Öğrencilerinde Nomofobi ve Sosyal Anksiyete Düzeylerinin Karşılaştırılması
}

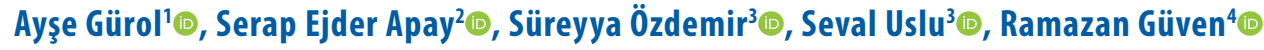

'Erzurum Teknik Üniversitesi, Sağlık Bilimleri Fakültesi, Erzurum, Türkiye ${ }^{2}$ Atatürk Üniversitesi, Sağlık Bilimleri Fakültesi, Erzurum, Türkiye ${ }^{3}$ Atatürk Üniversitesi, Sağlık Hizmetleri Meslek Yüksekokulu, Erzurum, Türkiye

"Sağlık Bilimleri Üniversitesi, Kanuni Sultan Süleyman Eğitim ve Araştırma Hastanesi, İstanbul, Türkiye

Ayşe Gürol, Doç. Dr. Serap Ejder Apay, Doç. Dr. Süreyya Özdemir, Öğr. Gör. Seval Uslu, Okutman Ramazan Güven, Doç. Dr.

Iletişim:

Doç. Dr. Ayşe Gürol

Erzurum Teknik Üniversitesi, Sağlık Bilimleri

Fakültesi, Erzurum, Türkiye

Tel: +904424445388

E-Posta: ayseparlak42@gmail.com
Gönderilme Tarihi : 17 0cak 2019

Revizyon Tarihi : 28 Temmuz 2019

Kabul Tarihi

: 23 Eylül 2019
ÖZET

Amaç: Bu çalışmanın amacı, üniversite öğrencilerinin nomofobi ve sosyal anksiyete düzeylerini belirlemek ve karşılaştırmaktır.

Yöntem: Tanımlayıcı ve ilişki arayııı tipte olan araştırma Nisan - Haziran 2017 tarihleri arasında, Atatürk Üniversitesi'nde gerçekleştirildi. Akıllı telefon kullanan ve çalışmaya katılmayı kabul eden 703 üniversite öğrencisi çalışmaya dahil edildi. Verilerin toplanmasında Kişisel Bilgi Formu, Nomofobi Ölçeği ve Liebowitz Sosyal Anksiyete Ölçeği kullanııldı. Araştırmaya başlamadan önce, etik onay ve araştırmanın yapılacağı birimlerden yazılı izin aldı. Veriler araştırmacı tarafından belirlenen sınıflarda herhangi bir ders saati bitiminde öğrenciler ile yüz yüze görüşme tekniği kullanılarak toplandı. Veriler SPSS 20.0 paket programı kullanılarak analiz edildi.

Bulgular: Çalışmaya katılan öğrencilerin \%78,38'i kadın, \%21,62'si erkek, \%54,62'si 1. sınıf öğrencisidir. Öğrencilerin $\% 31,86$ 'sı 5 yıl ve üzeri akıllı cep telefonu kullandığını, \%8,25'i son bir yıldır akıllı telefon kullandığını bildirmiştir. Öğrencilerin genel ağırıklı not ortalamalarının $2,57 \pm 0,68$ olduğu, Nomofobi Ölçeğinden $75,28 \pm 25,38$ puan, Liebowitz Sosyal Anksiyete ölçeğinin sosyal fobik korku alt ölçeğinden $50,68 \pm 12,67$ puan ve sosyal fobik kaçınma alt ölçeğinden $50,00 \pm 13,89$ puan aldıkları belirlendi. Nomofobi ölçeği ile Sosyal Anksiyete ölçeğinin toplam puanları arasında istatistiksel olarak anlamlı pozitif yönde güçlü bir ilişki saptandı ( $r=0,195, p<0,05 ; r=0,193, p<0,05)$.

Sonuç: Elde edilen bulgulara göre öğrencilerin nomofobi düzeylerinin ortalamanın üzerinde olduğu saptandı. Genç nüfusun mobil cihaz kullanma oranının yüksekliği düşünüldüğgünde, yeni bir tehlike ile karşı karşıya olunduğu söylenebilir.

Anahtar sözcükler: Anksiyete, nomofobi, öğrenci, sosyal, üniversite

\section{A COMPARISON OF NOMOPHOBIA AND SOCIAL ANXIETY LEVELS OF UNIVERSITY STUDENTS}

\section{ABSTRACT}

Objectives: The aim of this study is to determine and compare the nomophobia and social anxiety levels of university students.

Method: The descriptive and cross-sectional study was carried out between April and June 2017 at Atatürk University. 703 university students who used smartphones and agreed to participate in the study were included in it. Personal Information Form, Nomophobia Scale and the Liebowitz Social Anxiety Scale were used for data collection. Before starting the study, it received the ethics committee approval and written permission in which the study was carried out. Data were analysed using SPSS 20.0 package program.

Findings: $78.38 \%$ of the students were female, $21.62 \%$ were male and $54.62 \%$ were 1 st-grade students. $31.86 \%$ of students reported using smartphones over 5 years and $8.25 \%$ reported using smartphones for the last one year. It was determined that students' general weighted grade point average was $2.57 \pm 0.68$ and $75.28 \pm 25.38$ points from Nomophobia Scale, $50.68 \pm 12.67$ scores from social phobic fear subscale of the Liebowitz Social Anxiety Scale, and $50.00 \pm 13.89$ from social phobic avoidance subscale. A statistically significant positive correlation was found between the total scores of the Nomophobia Scale and the Liebowitz Social Anxiety Scale $(r=0.195, p<0.05 ; r=0.193, p<0.05)$.

Result: According to the findings, it was found that the students'nomophobia levels were above the average. Considering the high rate of using mobile devices in young people, it can be said that our country has a new social problem.

Keywords: Anxiety, nomophobia, student, social, university 
G ünümüzde teknoloji yaşamın vazgeçilmez bir parçası haline gelmiştir (1). Cep telefonu kullanımı, internet erişim kolaylığı ve mobil cihazların kapasitesinin artması gibi nedenlerden dolayı hızla artış göstermektedir $(1,2)$. Android işlemcili telefonların piyasadaki pazar payı İspanya'da \%90, Almanya'da ise \%79,8'dir (3). Türkiye İstatistik Kurumu (TÜIK) (2019) raporuna göre Türkiye'de 16-74 yaş arasında internet kullanım oranı \%75,3, hanelerin yüzde 88,3'ü evden internete erişim imkânına sahiptir. Genel olarak, internet erişimi olan hanelerde yetişkin insanların \%98'i cep telefonu kullanırken, bunların \%77'si akılı telefon kullanmaktadır. Masaüstü bilgisayar veya laptop kullananların oranı \%48 iken, tablet kullananların oranı \%25'tir (4).

Cep telefonun yaygınlaşmasına paralel olarak, aşırı kullanımdan bağımlılığa uzanan bir aralıkta cep telefonu ile ilgili farklı sorunlar da araştırma konusu olmaya başlamıştır. Bireyin mobil cihazına erişemediğinde veya mobil cihaz üzerinde iletişim kuramadığında yaşadığı korku olarak tanımlanan nomofobi (nomophobia), modern çağın yeni fobisi olarak adlandırılmaktadır $(5,6)$. Mobil cihaz bağımlılarının, anksiyete bozuklukları gibi diğer psikososyal sorunlar yaşadıkları ifade edilmektedir. Nomofobik birey, telefonunu yanına almayı unuttuğunda, telefonunun şarjı bittiğinde ya da kapsama alanı dışında olduğunda anksiyete duymaya başlamaktadır (7).

Akıllı telefonların yaygınlığının artışına paralel olarak nomofobi, 100 ergenden 76'sında görülmektedir $(1,8)$. Ergen ve gençlerde cep telefonuna sahip olma oranının \%76'ya ulaştığı ve \%40'ının ikinci bir cep telefona sahip olduğu bildirilmektedir (8). Yapılan bir çalışmada üniversite öğrencilerinin üçte birinin nomofobik olduğu belirtilmektedir (9). Türkiye'de yapılan bir araştırmada, üniversite öğrencilerinin \%42,6'sının nomofobik olduğu, en büyük korkularının iletişim kuramamak ve bilgiye erişememek olduğu bildirilmiştir (10). Spitzer (11), akıllı telefonların dikkat bozukluğu, empati bozukluğu, akademik başarıda azalma, obezite, anksiyete ve depresyon gibi risklerinin olabileceğini belirtmiştir. King ve arkadaşları (12) cep telefonu bağımlılığının, kişilerde sosyal fobi veya bağımlı kişilik bozukluğu gibi hastalıklara neden olabileceğini bildirmiştir.

Cep telefonu kullanım oranının yüksekliği düşünüldüğünde, genç neslin yeni bir tehlike ile karşı karşıya olduğu söylenebilir. Bu nedenle çalışma, üniversite öğrencilerinin nomofobi ve sosyal anksiyete düzeylerini belirlemek ve karşılaştırmak amacıyla yapıldı.

\section{Yöntem}

Tanımlayıcı ve ilişki arayıcı olarak planlanan araştırma, Atatürk Üniversitesi'nde Nisan-Haziran 2017 tarihleri arasında yapıldı. Atatürk Üniversitesi'nde 23 Fakülte, 1 Yüksekokul, 1 Konservatuvar, 12 Meslek Yüksekokulu, 8 Enstitü, 25 Araştırma ve Uygulama Merkezi bulunmakta ve toplam 210 bin öğrenci eğitim görmektedir. il merkezinde yer alan Atatürk Üniversitesi Fakülte ve Meslek Yüksekokulları bünyesinde 55,829 öğrenci örgün öğrenim görmektedir.

Çalışmanın evrenini Atatürk Üniversitesi'nde 2016-2017 eğitim öğretim dönemi Bahar yarıyılında ders kaydı yapmış bütün öğrenciler oluşturdu. Araştırmanın örneklemini belirlemede tabakalı örnekleme yöntemi kullanılarak bir fakülte ve bir yüksekokul seçildi. Evrendeki birey sayısının bilindiği durumlarda örneklem hesaplama formülünden yararlanılarak 0,05 güven aralığında 383 öğrencinin çalışmaya alınması hedeflendi. Bütün sınıflar numaralandırılacak basit rastgele sayılar tablosu kullanılarak örnekleme dahil olacak sınıflar belirlendi. Akıllı telefon kullanan ve çalışmaya katılmayı kabul eden 703 öğrenci çalışmaya dahil edildi.

Verilerin toplanmasında Kişisel Bilgi Formu, Nomofobi Ölçeği (NMP-Q) ve Liebowitz Sosyal Anksiyete Ölçeği kullanıldı.

Kişisel Bilgi Formu: Formda öğrencilerin okulu, sınıfı, cinsiyeti, yaş, akıllı telefon kulanım süresi ve genel ağırlıklı not ortalaması bilgilerini içeren toplam 6 soru bulunmaktadır.

Nomofobi Ölçeği (NMP-Q): Çalışmada öğrencilerin nomofobi skorlarını ölçmek için Yildirim ve Correira (6) tarafından geliştirilen ve Yildirim ve arkadaşları (10) tarafından Türkçe'ye uyarlanan Nomofobi Ölçeği kullanıldı. Ölçek 7'li likert tipine göre maddelenmiş olup, toplam 20 maddeden oluşmaktadır. Ölçek, Bilgiye Erişememe (4 madde), Rahatlıktan Feragat etme (5 madde). Bağlantıyı Kaybetme (5 madde), Iletişime Geçememe (6 madde) olmak üzere dört alt boyuttan oluşmaktadır. Kişilerin ölçekten alınan toplam puana göre nomofobi seviyeleri; $=20$ puan nomofobi yok, $21 \leq$ puan $<60$ hafif düzeyde, $60 \leq$ puan $<100$ orta düzeyde, $100 \leq$ puan $\leq 140$ ağır düzeyde nomofobik olarak sınıflandırılmaktadır. Yıldırım ve ark. (10) tarafından yapılan çalışmada ölçeğin güvenilirlik değeri (Cronbach Alpha) 0,92 olarak alt boyutlarının değeri ise 0,$90 ; 0,74$; 0,94 ve 0,91 olarak hesaplanmıştır. Bu çalışmada ölçeğin Cronbach's alfa değeri 0,92, alt boyutlarının değeri ise sırayla; $0,83,0,80,0,90,0,90$ olarak hesaplandı.

Liebowitz Sosyal Anksiyete Ölçeği (LSAÖ): Ölçek, bireylerin, korku ve/veya kaçınma davranışı gösterdikleri sosyal ilişki ve performans durumlarını değerlendirmek 
üzere geliştirilmiştir (13). Ölçek 4'lü likert tipine göre olup sorular, bireylerin son bir hafta içindeki korku ve kaçınmasının şiddeti göz önüne alınarak cevaplandırılmaktadır. Toplam puan, korku ve kaçınma puanlarının toplanması ile elde edilir. Ülkemizde geçerlik ve güvenirlik çalışması Dilbaz ve Güz (14) tarafından yapılmış olan LSAÖ'nün iç tutarlığı (Cronbach alpha) 0,96 bulunmuştur. Bu çalışmada Liebowitz Sosyal Anksiyete Ölçeği Sosyal Fobik Korku alt ölçeği için Cronbach's alfa katsayısı 0,88, Sosyal Fobik Kaçınma Cronbach's alfa katsayısı 0,92 olarak belirlendi.

Araştırmada veri toplama süreci, araştırmacılar tarafından üniversite öğrencilerinin gönüllü katılımı esas alınarak gerçekleştirildi. Araştırmaya başlamadan önce, Atatürk Üniversitesi Sağlık Bilimleri Fakültesi Etik Kurul Başkanlığı'ndan (20 17/03/02 sayılı, 22/02017 tarihli) ve araştırmanın yapılacağı birimlerden yazılı izin alındı. Araştırma verilerini toplamaya başlamadan önce; öğrencilere araştırma hakkında bilgi verilerek ve araştırmaya ilişkin soruları yanıtlandı. Veriler araştırmacı tarafından ilgili fakülte ve yüksekokulda belirlenen sınıflarda herhangi bir ders saati bitiminde öğrenciler ile yüz yüze görüşme tekniği kullanılarak toplandı.

Araştırmada analizler SPSS 20.0 (The Statistical Package for the Social Sciences) paket programı kullanılarak gerçekleştirildi. Araştırmada yüzde, ortalama, standart sapma ve korelasyon analizi kullanıldı. Yapılan istatistiksel çözümlemelerde istatistiksel anlamlılık düzeyi 0,05 olarak alındı.

\section{Bulgular}

Çalışmaya katılan öğrencilerin $\% 78,4$ 'ünün kadın, $\% 21,6$ 'sının erkek, \%54,6'sının 1. sınıf öğrencisi olduğu, $\% 31,9^{\prime}$ unun beş yıl ve üzeri akıllı cep telefonu kullandığı, \%8,3'ünün son bir yıldır akıllı telefon kullandığı saptandı (Tablo 1). Öğrencilerin genel ağırlıklı not ortalamalarının $2,57 \pm 0,68$ olduğu, yaş ortalamasının ise $20,31 \pm 2,09$ yıl olduğu belirlendi.

Çalışmada öğrencilerin Nomofobi ölçeğinden toplamda $75,28 \pm 25,38$, bilgiye erişememe alt boyutundan $16,22 \pm 6,61$, rahatlıktan feragat etme alt boyutundan $18,37 \pm 7,88$, iletişim kuramama alt boyutundan $26,38 \pm 9,92$, çevrimiçi bağlantıyı kaybetme alt boyutundan $14,29 \pm 8,18$ puan aldıkları saptandı (Tablo 2).

Çalışmada öğrencilerin nomofobi ölçeğinden aldıkları toplam puan ortalamalarına göre sınıflandırılması incelendiğinde; 703 öğrencinin yalnızca altısında nomofobinin olmadığı, 176 (\%25,04)'sında hafif düzeyde nomofobi, 393 (\%55,90)'ünde orta düzeyde nomofobi, 128 $(\% 18,21)$ 'inde ağır düzeyde nomofobi olduğu belirlendi (Tablo 3).

\section{Tablo 1. Öğrencilerin tanıtıcı özelliklerin dağılımı $(n=703)$}

\begin{tabular}{|c|c|c|}
\hline Özellikler & \multicolumn{2}{|c|}{ Ortalama \pm Standart sapma } \\
\hline Yaşı (yıl) & \multicolumn{2}{|c|}{$20,31 \pm 2,09$} \\
\hline \multirow[t]{2}{*}{ AGNO } & \multicolumn{2}{|c|}{$2,57 \pm 0,68$} \\
\hline & Sayı & Yüzde \\
\hline \multicolumn{3}{|l|}{ Cinsiyeti } \\
\hline Kadın & 551 & 78,38 \\
\hline Erkek & 152 & 21,62 \\
\hline \multicolumn{3}{|l|}{ Okul } \\
\hline Yüksekokul & 442 & 62,87 \\
\hline Fakülte & 261 & 37,13 \\
\hline \multicolumn{3}{|l|}{ Sinıfı } \\
\hline 1. & 384 & 54,62 \\
\hline 2. & 198 & 28,17 \\
\hline 3. & 73 & 10,38 \\
\hline 4. & 48 & 6,83 \\
\hline \multicolumn{3}{|c|}{ Akıllı telefon kullanma süresi } \\
\hline $1 \mathrm{yll}$ & 58 & 8,25 \\
\hline $2 \mathrm{yll}$ & 118 & 16,79 \\
\hline $3 \mathrm{yll}$ & 140 & 19,91 \\
\hline $4 \mathrm{yll}$ & 163 & 23,19 \\
\hline 5 yıl ve üzeri & 224 & 31,86 \\
\hline
\end{tabular}

Tablo 2. Öğrencilerin Nomofobi Ölçeği ve alt boyutlarından aldıkları puan ortalamaları

\begin{tabular}{|c|c|c|c|c|}
\hline Alt ölçek & Min. & Max. & $\begin{array}{c}\text { Ortalama } \pm \\
\text { Standart sapma }\end{array}$ & $\begin{array}{c}\text { Cronbach's } \\
\text { alpha katsayısı }\end{array}$ \\
\hline Bilgiye erişememe & 4,00 & 28,00 & $16,22 \pm 6,61$ & 0,83 \\
\hline $\begin{array}{l}\text { Rahatlıktan } \\
\text { feragat etme }\end{array}$ & 5,00 & 35,00 & $18,37 \pm 7,88$ & 0,80 \\
\hline İletişim kuramama & 6,00 & 42,00 & $26,38 \pm 9,92$ & 0,90 \\
\hline $\begin{array}{l}\text { Çevrimiçi bağlantıyı } \\
\text { kaybetme }\end{array}$ & 5,00 & 35,00 & $14,29 \pm 8,18$ & 0,90 \\
\hline Toplam puan & 20,00 & 140,00 & $75,28 \pm 25,38$ & 0,92 \\
\hline
\end{tabular}

Tablo 3. Öğrencilerin Nomofobi Ölçeğinden aldıkları puanlara göre sinfilandirlmas|

\begin{tabular}{lcc} 
Nomofobi & Sayı & Yüzde \\
\hline Yok $(=20)$ & 6 & 0,85 \\
Hafif $(\leq 21-<60)$ & 176 & 25,04 \\
Orta $(\leq 60-<100)$ & 393 & 55,90 \\
Ağır $(\leq 100-140)$ & 128 & 18,21
\end{tabular}


Öğrencilerin Liebowitz Sosyal Anksiyete ölçeğinden toplamda $100,68 \pm 24,75$, sosyal fobik korku alt ölçeğinden $50,68 \pm 12,67$ ve sosyal fobik kaçınma alt ölçeğinden $50,00 \pm 13,89$ puan aldıkları belirlendi (Tablo 4).

Çalışmada Nomofobi ölçeği ve alt boyutları ile Liebowitz Sosyal Anksiyete Ölçeği ve alt boyutlarından alınan puan ortalamaları arasında istatistiksel olarak anlamlı pozitif yönde güçlü bir ilişki saptandı (Tablo 5, p<0,05).

Tablo 4. Öğrencilerin Liebowitz Sosyal Anksiyete Ölçeği ve alt boyutlarından aldıkları puan ortalamaları

\begin{tabular}{lcccc}
$\begin{array}{l}\text { Liebowitz sosyal } \\
\text { anksiyete ölçeği }\end{array}$ & Min. & Max. & $\begin{array}{c}\text { Ortalama } \pm \\
\text { Standart sapma }\end{array}$ & $\begin{array}{c}\text { Cronbach's alpha } \\
\text { katsayısı }\end{array}$ \\
\hline $\begin{array}{l}\text { Sosyal Fobik } \\
\text { Korku }\end{array}$ & 24,00 & 96,00 & $50,68 \pm 12,67$ & 0,88 \\
$\begin{array}{l}\text { Sosyal Fobik } \\
\text { Kaçınma }\end{array}$ & 24,00 & 96,00 & $50,00 \pm 13,89$ & 0,92 \\
\hline $\begin{array}{l}\text { Toplam } \\
\text { 4o }\end{array}$ & 48 & 192 & $100,68 \pm 24,75$ & 0,94
\end{tabular}

Tablo 5. Öğrencilerin Nomofobi Ölçeği ve alt boyutlarından alddkları puan ortalamaları ile Liebowitz Sosyal Anksiyete Ölçeği ve alt boyutlarından aldıkları puan ortalamaları arasındaki ilişki

\begin{tabular}{|c|c|c|c|c|c|c|}
\hline \multirow[t]{3}{*}{ Nomofobi ölçeği } & \multicolumn{6}{|c|}{ Liebowitz sosyal anksiyete ölçeği } \\
\hline & \multicolumn{2}{|c|}{ Korku } & \multicolumn{2}{|c|}{ Kaçınma } & \multicolumn{2}{|c|}{ Toplam puan } \\
\hline & $r$ & $p$ & $r$ & $p$ & $r$ & $p$ \\
\hline Bilgiye erişememe & 0,142 & 0,000 & 0,139 & 0,000 & 0,150 & 0,000 \\
\hline $\begin{array}{l}\text { Rahatlıktan } \\
\text { feragat etme }\end{array}$ & 0,189 & 0,000 & 0,189 & 0,000 & 0,203 & 0,000 \\
\hline İletişim kuramama & 0,156 & 0,000 & 0,134 & 0,000 & 0,155 & 0,000 \\
\hline $\begin{array}{l}\text { Çevrimiçi bağlantıyı } \\
\text { kaybetme }\end{array}$ & 0,119 & 0,002 & 0,142 & 0,000 & 0,141 & 0,000 \\
\hline Toplam Puan & 0,195 & 0,000 & 0,193 & 0,000 & 0,208 & 0,000 \\
\hline
\end{tabular}

\section{Tartışma}

Akıllı cep telefonları, birçok kolaylıklar sağlayan önemli teknolojik buluşlardan biridir. Bunun yanısıra cep telefonlarının aşırı derecede kullanımı, kullanıcının biyolojik, fizyolojik, psikolojik ve sosyal gelişimini olumsuz olarak etkileyebilmektedir $(15,16)$. Bu araştırmada üniversite öğrencilerinin akıllı telefon bağımlılık düzeyleri ve sosyal fobik korku ve kaçınma düzeyleri farklı değişkenler açısından incelenmiştir.
Çalışmada öğrencilerin \%55,90'ının orta düzeyde nomofobik olduğu belirlendi (Tablo 3). İngiltere'de yapılan bir çalışmada, cep telefonu kullanıcılarının \%53'ünün nomofobik davranış sergiledikleri belirtilmiştir (17). Hindistan'da yapılan başka bir çalışmada ise öğrencilerin \%51'inin orta seviyede nomofobik davranışlar sergiledikleri saptanmıştır (18). Yıldırım ve ark. (10), öğrencilerin \%42,6'sının nomofobik davranışlara sahip olduğunu; Sharma ve ark. (19), öğrencilerin yaklaşık \%73'nün nomofobik olduğunu saptamışlardır. Son yıllarda nomofobik davranış gösteren telefon kullanıcılarının oranında artış olduğu bildirilmektedir (20). Çalışmadan elde edilen bulgular literatürle benzerlik göstermektedir.

Çalışmada öğrencilerin nomofobi ölçeği ve alt boyutlarından aldıkları toplam puan ortalamaları ile Liebowitz'in sosyal kaygı ve kaçınma ölçeklerinden aldıkları puan ortalamaları arasında pozitif yönlü anlamlı bir ilişki saptanmıştır (Tablo 5). Spitzer (11), akıllı telefonların bağımlılık, dikkat bozukluğu, empati bozukluğu, okul başarısında düşüş, obezite, kaygı, depresyon ve kişilik bozukluğu gibi olumsuz etkilerine dikkat çekmiştir. Yaşları 18-24 arası olan gençlerin \%77'si cep telefonlarını kaybetme fikrinin kendilerinde kaygı oluşturduğunu ve bu anlamda korku hissettiklerini ifade etmişlerdir (20). Yapılan bir çalışmada bir grup üniversite öğrencisinin cep telefonlarını kapatmaları ve kaldırmaları istenmiştir. Cep telefonu kapatılan öğrencilerin kaygı düzeyinin yükseldiği saptanmıştır (21). Yılmaz ve ark. (22) ergenlerde problemli cep telefonu kullanımı ile sosyal kaygı arasında anlamlı bir ilişki bulmuşlardır.

\section{Sonuç}

Bu çalışma, oldukça yeni bir kavram olan nomofobi ile sosyal anksiyete arasındaki ilişkiyi incelemiştir. Yapılan analizler sonucunda nomofobi düzeyi yüksek olan üniversite öğrencilerinin sosyal anksiyete düzeylerinin de arttığı ve aralarında anlamlı bir ilişki olduğu bulunmuştur. Sonuçların genellenebilmesi adına farklı bölgelerde ve bölümlerdeki öğrenciler üzerinde araştırmalar yapılması ve kullanıcıların alışkanlıkları, davranışları ve duyguları ile olan ilişkisinin incelenmesi önerilmektedir. 


\section{Kaynaklar}

1. Adnan M, Gezgin DM. A Modern Phobia: Prevalence of Nomophobia among College Students. Ankara University Journal of Faculty of Educational Sciences 2016;49:141-58. https://dergipark.org.tr/en/ download/article-file/508596

2. Bian M, Leung L. Linking loneliness, shyness, smartphone addiction symptoms, and patterns of smartphone use to social capital. Soc Sci Comput Rev 2014;33:61-79. [CrossRef]

3. O'Dea S. Statistics and facts about the smartphone market in Europe. Statista 2017. https://www.statista.com/topics/3341/ smartphone-market-in-europe/

4. TUiK. Yıllara, Yaş Grubu ve Cinsiyete Göre Nüfus, Genel Nüfus Sayımları.2019. www.tuik.gov.tr adresinden erişildi https://internet. btk.gov.tr/istatistikler. Erişim tarihi: 14 Şubat 2020

5. King ALS, Valença AM, Silva AC, Baczynski T, Carvalho MR, Nardi AE. Nomophobia: dependency on virtual environments or social phobia? Comput Hum Behav 2013;29:140-4. [CrossRef]

6. Yıldırım C, Correia AP. Exploring the dimensions of nomophobia: Development and validation of a self-reported questionnaire. Comput Hum Behav 2015;49:130-7. [CrossRef]

7. Dixit S, Shukla H, Bhagwat A, Bindal A, Goyal A, Zaidi A, Shrivastava A. A study to evaluate mobile phone dependence among students of a medical college and associated hospital of central India. Indian J Community Med 2010;35:339-41. [CrossRef]

8. Şar AH, Işıklar A. Problemli mobil telefon kullanım ölçeğinin Türkçeye uyarlaması. Int J Hum Sci 2012;9:264-75. https://arastirmax.com/tr/ system/files/dergiler/161047/makaleler/9/2/arastrmx_161047_9_ pp_264-275.pdf

9. Tavolacci MP, Meyrignac G, Richard L, Dechelotte P, Ladner J. Problematic use of mobile phone and nomophobia among French college students. Eur J Public Health 2015;25:ckv172-088. [CrossRef]

10. Yıldırım C, Sumuer E, Adnan M, Yıldırım S. A growing fear: Prevalence of nomophobia among Turkish college students. Inform Dev 2016;32:1322-31. [CrossRef]

11. Spitzer M. M-Learning? When it comes to learning, smartphones are a liability, not an asset. Trends Neurosci Educ 2015;4:87-9. [CrossRef]
12. King ALS, Valença AM, Silva AC, Sancassiani F, Machado S, Nardi AE. "Nomophobia": Impact of cell phone use interfering with symptoms and emotions of individuals with panic disorder compared with a control group. Clin Pract Epidemiol Ment Health 2014;10:28-35. [CrossRef]

13. Liebowitz MR. Social phobia. Mod Probl Pharmacopsychiatry 1987;22:141-73. [CrossRef]

14. Dilbaz N, Güz H. Liebowitz sosyal kaygı ölçeğinin geçerlik ve güvenirliği 37. Ulusal Psikiyatri Kongresi, İstanbul, 2-6 Ekim, 2001.

15. Pearson C, Hussain Z. Smartphone addiction and associated psychological factors. Addicta 2016;3:193-207. [CrossRef]

16. Soni R, Upadhyay $R$, Jain M. Prevalence of smart phone addiction, sleep quality and associated behaviour problems in adolescents. Int J Res Med Sci 2017;5:515-9. [CrossRef]

17. Mail Online. Nomophobia is the fear of being out of mobile phone contact -and it's the plague of our 24/7 age, 2008. http://www. dailymail.co.uk/news/article-550610/Nomophobia-fear-mobilephonecontact-plague-24-7-age.html

18. Abraham N, Mathias J, Williams S. A Study to Assess the Knowledge and Effect of Nomophobia Among Students of Selected Degree Colleges in Mysore. Asian J Nurs Educ Res 2014;4:421-8. https:// ajner.com/HTMLPaper.aspx?Journal=Asian+Journal+of+Nursing+E ducation+and+Research\%3bPID\%3d2014-4-4-8

19. Sharma N, Sharma P, Sharma N, Wavare RR. Rising concern of nomophobia amongst Indian medical students. Int J Res Med Sci 2015;3:705-7. https://www.msjonline.org/index.php/ijrms/article/ view/1360

20. SecurEnvoy $66 \%$ of the population suffer from Nomophobia the fear of being without their phone, 2012. https://www.securenvoy.com/ en-gb/blog/66-population-suffer-nomophobia-fear-being-withouttheir-phone

21. Cheever NA, Rosen LD, Carrier LM, Chavez A. Out of sight is not out of mind: the impact of restricting wireless mobile device use on anxiety levels among low, moderate and high users. Comput Hum Behav 2014;37:290-7. [CrossRef]

22. Yılmaz G, Şar AH, Civan S. Ergenlerde Mobil Telefon Bağımlığı İle Sosyal Kaygı Arasındaki İlişkinin İncelenmesi. J Technol Addict Cyberbullying 2015;2:20-37. https://dergipark.org.tr/tr/download/ article-file/290283 